\title{
Influência dos Reguladores de Crescimento 2,4-D e BAP associados aos agentes solidificantes Ágar e Phytagel na Indução de calos de Crinum americanum L.
} (Amaryllidaceae)

\author{
Influence of 2,4-D and BAP Growth Regulators associated with Agar solidifying agents and \\ Phytagel on callus induction of Crinum americanum L. (Amaryllidaceae) \\ Influencia de los reguladores de crecimiento 2,4-D y BAP asociados con agentes solidificantes Agar \\ y Phytagel en la inducción de callos de Crinum americanum L. (Amaryllidaceae)
}

Recebido: 08/09/2021 | Revisado: 14/09/2021 | Aceito: 20/09/2021 | Publicado: 22/09/2021

\author{
Rosana Silva Corpes \\ ORCID: https://orcid.org/0000-0001-6357-8094 \\ Universidade Federal do Pará, Brasil \\ E-mail: rosanacorpes@hotmail.com \\ Alberdan Silva Santos \\ ORCID: https://orcid.org/0000-0003-1863-176X \\ Universidade Federal do Pará, Brasil \\ E-mail: alberdan.ufpa@gmail.com
}

\begin{abstract}
Resumo
Crinum americanum L. é uma planta monocotiledônea pertencente à família Amaryllidaceae que possui importância econômica por ser ornamental e farmacológica por conter alcalóides que podem apresentar ação anticolinisterásica em sua composição química. A indução de calos é importante tanto para produção de biomassa como para o acúmulo de metabólitos secundários, principalmente aos da classe dos alcaloides. Neste sentido, podem ser empregadas técnicas biotecnológicas como alternativa para viabilizar o processo. Atualmente, sabe-se que as plantas monocotiledôneas apresentam grandes dificuldades de serem cultivadas in vitro, dentre as quais se destaca a espécie $C$. americanum. Em função disso, este estudo teve o objetivo de demostrar as concentrações mais eficientes dos reguladores de crescimento 2,4-D e BAP associados aos agentes solidificantes Ágar e Phytagel para cultivo in vitro desta espécie com o intuito de apresentar alternativas para o aumento da produção de biomassa e auxiliar em estudos futuros na área de embriogênese somática e/ou para acúmulo de metabólitos secundários. Para a avaliação do desenvolvimento das células, observou-se o crescimento das mesmas em diâmetro e também se obteve a curva de crescimento dos calos através da amostragem por sacrifício. Observou-se que quando os calos friáveis são inoculados com o correto balanço entre os reguladores de crescimento no meio MS suplementado com sacarose $3 \%(\mathrm{~m} / \mathrm{v})$, que contenha o agente solidificante Phytagel a $0,2 \%(\mathrm{~m} / \mathrm{v})$, as células tendem a crescer com maior velocidade e consequentemente o ganho de biomassa é maior.
\end{abstract}

Palavras-chave: Alcalóides; Biotecnologia vegetal; Cultivo in vitro.

\begin{abstract}
Crinum americanum L. is a monocotyledonous plant belonging to the Amaryllidaceae family that has economic importance for being ornamental and pharmacological for containg alkaloids that can present anticholinesterase action in its chemical composition. Callus induction is important both for biomass production and for the accumulation of secondary metabolites, especially those of the alkaloid class. In this sense, biotechnological techniques can be used as an alternative to make the process viable. Nowadays, it is known that monocotyledonous plants present great difficulties to be cultivated in vitro, among which the species $C$. americanum stands out. As a result, the objective this study was to demonstrate the most efficient concentrations of growth regulators 2,4-D and BAP associated with solidifying agents Agar and Phytagel for in vitro cultivation of this species in order to present alternatives to increase production of biomass and help in future studies in the area of somatic embryogenesis and/or for accumulation of secondary metabolites. For the evaluation of cell development, growth in diameter was observed and the callus growth curve was also obtained through sacrificial sampling. It was observed that when the friable callus is inoculated with the correct balance between growth regulators in MS medium supplemented with 3\% sucrose (m/v), which contains the solidifying agent Phytagel at $0.2 \%(\mathrm{~m} / \mathrm{v})$, cells tend to grow faster and consequently the gain in biomass is greater.
\end{abstract}

Keywords: Alkaloids; Plant biotechnology; In vitro cultivation. 


\begin{abstract}
Resumen
Crinum americanum L. es una planta monocotiledónea perteneciente a la familia de las amaryllidaceae que tiene importancia económica ser ornamental e farmacologica por contener alcaloides que pueden presentar acción anticolinesterasa en su composición química. la inducción de callos es importante tanto para la producción de biomasa como el acumulo de metabolitos secundarios, especialmente los de la clase de alcaloides. En este sentido, las técnicas biotecnológicas se pueden utilizar como alternativa para viabilizar el proceso. Actualmente, se sabe que las plantas monocotiledóneas presentan grandes dificultades para ser cultivadas in vitro, entre las que destaca la especie $C$. americanum. Como resultado, este estudio tuvo como objetivo demostrar las concentraciones más eficientes de reguladores de crecimiento 2,4-D y BAP asociados con agentes solidificantes Agar y Phytagel para el cultivo in vitro de esta especie con el fin de presentar alternativas para incrementar la producción de biomasa y ayudar en estudios futuros en el área de embriogénesis somática o acumulación de metabolitos secundarios. Para la evaluación del desarrollo celular, se observó crecimiento en diámetro y también se obtuvo la curva de crecimiento del callo mediante muestreo de sacrificio. Se observó que cuando se inoculan callos friables con el equilibrio correcto entre reguladores de crecimiento en medio MS suplementado con sacarosa al 3\% (m/v), que contiene el agente solidificante Phytagel al $0.2 \%$ (m / v), las células tienden a crecer más rápido y consecuentemente se gano mas biomasa.
\end{abstract}

Palabras clave: Alcalóides; Biotecnologia vegetal; Cultivo in vitro.

\title{
1. Introdução
}

Realizar estudos voltados para cultura de tecidos vegetais proporcionam ao pesquisador uma série de desafios, uma vez que esta constitui um conjunto de técnicas com diversas vantagens e aplicações e é através da mesma que diferentes partes de uma planta podem ser isoladas (explantes) e inseridas em um meio de cultura com o balanço de nutrientes que serão muito úteis ao processo de diferenciação celular.

O desenvolvimento destas células podem dar origem a novos tecidos e órgãos para o estabelecimento de novas plantas e durante o desenvolvimento e execução das atividades envolvendo o cultivo in vitro, vários fatores precisam ser considerados que vão desde a escolha do explante com posterior obtenção de material axênico até o estabelecimento da cultura em um meio adequado.

Para o cultivo in vitro, vários meios de cultura são utilizados como opção e dependendo da finalidade a qual os mesmos se destinam, podem ser utilizados reguladores de crescimento em adição a este meio nutritivo ou diferentes agentes solidificantes. No que diz respeito aos reguladores de crescimento, podem ser utilizadas as auxinas, citocininas e giberelinas, já em relação aos agentes solidificantes, o ágar e o phytagel são os mais comumente utilizados.

Os reguladores de crescimento possuem uma grande importância para o desenvolvimento celular, uma vez que é através do balanço dos mesmos que é possível verificar qual será a tendência do comportamento das células, pois os mesmos interferem diretamente na fisiologia das plantas. Segundo Cordeiro, et al. (2004), os fitorreguladores que podem estar no meio de cultura estão diretamente relacionados com o crescimento e a maior parte do padrão de desenvolvimento dos cultivos in vitro. Estudos realizados com a videira por Fagundes (2020) relatam que os reguladores de crescimento de plantas podem desempenhar um papel fundamental na redução do crescimento vegetativo excessivo, afetando positivamente na produção e a qualidade dos vegetais.

As auxinas e citocininas são extremamente importantes para o crescimento das plantas e seus principais processos de desenvolvimento. Para Costa (2006), cada tipo de célula, possui a necessidade de se desenvolver em um meio de cultura específico que contenha adequadamente os nutrientes e os agentes indutores necessários ao desenvolvimento destas células. Os autores Almeida e Rodrigues (2016) relatam que os fitormônios e/ou reguladores de crescimento podem interferir no desenvolvimento vegetal. Neste sentido as auxinas podem regular e influenciar diversas respostas na planta, como tropismos, dominância apical emissão de raízes, além de respostas ao nível celular como a divisão e a diferenciação. Em relação às citocininas, estas podem atuar a nível celular induzindo a expressão de determinados genes, promovendo a mitose e o desenvolvimento dos cloroplastos a nível dos órgãos, esta também induz a formação de brotos, além de influenciar na dominância apical e na inibição do crescimento das raízes (Yew et al., 2010). 
Observando a importância que tanto as auxinas como citocininas possuem para o desenvolvimento dos vegetais podemos dizer que o correto balanço dos reguladores de crescimento são de extrema importância para os vegetais e quando este ajuste é feito dentro das técnicas contidas na cultura de tecidos é possível observar diferenças na quantidade e na taxa dos padrões de crescimento dos explantes.

Os estudos realizados por Jardim et al. (2010) com Aniba rosaeodora Ducke relatam que uso de auxinas e citocininas foram preponderantes para a formação de calos e raízes nos explantes desta espécie e os mesmos sugerem que quando se tem altas concentrações de auxinas, ocorre a formação de raízes; entretanto quando as taxas de citocininas são baixas, ocorre a formação de gemas adventícias e o produto de uma relação intermediária entre estes reguladores resulta na geração de calos.

Oliveira et al. (2019) em seus estudos realizados com H. speciosa sugerem que concentrações elevadas da citocinina, possivelmente podem apresentar efeito tóxico e interferir na multiplicação e desenvolvimento dos explantes e consequentemente contribuir para sua degradação. Paralelamente ao uso dos reguladores de crescimento, a escolha do agente solidificante do meio de cultura também se torna importante, uma vez que o mesmo pode interferir nas etapas de crescimento celular, o que pode ser muito importante quando o objetivo é produzir células de uma determinada espécie em larga escala.

A cultura in vitro é uma ferramenta importante para a rápida multiplicação de plantas que apresentam características medicinais (Yew et al., 2010). Ela também é importante para a extração de produtos provenientes do metabólismo secundário. A espécie Crinum americanum L. envolvida neste estudo pertence à família Amaryllidaceae e sua escolha foi feita com base em estudos anteriores realizados por Araújo et al., (2018), onde se detectou a presença de alcaloides que foram extraídos dos bulbos da planta silvestre.

$\mathrm{Na}$ literatura já existem vários relatos de alcaloides que foram obtidos a partir dos extratos de plantas de Amaryllidaceae e estes são amplamente utilizados em investigações químicas e farmacológicas. Neste contexto, destaca-se a ação antitumoral, anti-inflamatória, antiviral, antimalárica e analgésica. Atualmente, já existe um real aumento da produção de plantas com atividades biológicas relacionadas principalmente à classe dos alcalóides e flavonoides (Berkov, 2012). Existem relatos na literatura quanto à presença de licorina nos extratos de $C$. amaricanum e este é tido como um alcalóide que possuí uma forte inibição na germinação devido ao mesmo possuir atividades alelopáticas e também produzir aleloquímicos. Neste aspecto, esta planta amplia as possibilidades de controlar espécies invasoras através da elaboração de um herbicida natural. (Ribeiro et al., 2009)

Sabendo-se que o cultivo in vitro de células vegetais amplia as possiblidades para o estudo dos principais metabólitos secundários de diversas espécies, o mesmo também se torna uma alternativa para evitar que no futuro estas espécies não apresentem risco de extinção, pois estudos desenvolvidos por Corpes, et al., (2019) apontam que plantas cultivadas in vitro podem apresentar semelhanças na composição química em relação as plantas cultivadas in vivo. Deste modo, conhecer as condições ideais para que um determinado tipo de célula seja cultivado é primordial para o sucesso nos trabalhos envolvendo o cultivo in vitro de células e/ou tecidos vegetais.

Com base nestes aspectos, este estudo laboratorial teve o intuito de demonstrar quais são as melhores condições para o cultivo in vitro de C. americanum associando as concentrações dos reguladores de crescimento 2,4-Diclorofenoxiacético (2,4D) e 6-Benzilaminopurina (BAP) ao agente solidificante Ágar ou Phytagel para a proliferação de calos friáveis desta espécie.

\section{Material e Métodos}

\subsection{Estabelecimento da cultura de calos e obtenção das amostras}

A obtenção da cultura de calos foi iniciada a partir de explantes obtidos de embriões e Plântulas axênicas que foram cultivadas in vitro em meio MS (Murashige \& Skoog, 1962). O processo para indução destes calos foi previamente estabelecido por Corpes et al. (2020). A indução ocorreu em meio de cultura MS suplementado com reguladores de 
crescimento e sob as diferentes concentrações 2.0, 0.5, 0.2, 1.0 e $3.0 \mathrm{mg} . \mathrm{L}^{-1}$ de 2,4-D combinado com 0.1, 0.2 ou $0.5 \mathrm{mg}$. L ${ }^{1}$ de BAP. Todas estas concentrações foram provenientes de uma matriz experimental. O trabalho foi realizado no LabISisBio (Laboratório de Investigação sistemática em Biotecnologia e Biodiversidade molecular) da Universidade Federal do Pará dentro da linha de pesquisa de Biotecnologia Vegetal. A espécie em questão está devidamente cadastrada com registro de atividades de acesso ao Patrimônio Genético e do Conhecimento Tradicional Associado (SisGen) sob número AA2BB8A.

\subsection{Análises do desenvolvimento celular}

O processo de desenvolvimento e proliferação celular foi reproduzido de forma contínua na concentração ideal para proliferação de calos friáveis descrita por Corpes et.al (2020) que foi a de $3.0 \mathrm{mg}$. L ${ }^{-1}$ de 2,4-D e $0.1 \mathrm{mg}$. L ${ }^{-1} \mathrm{de}$ BAP, modificando apenas os agentes solidificantes e a presença e/ou ausência do agente antioxidante o que resultou em 4 diferentes tratamentos sendo estes: T1: Phytagel 0,2 \% (m/v) + PVP 3\% (v/v); T2: Ágar 0,7\% (m/v) + PVP 3\% (v/v); T3: Phytagel 0,2\% $(\mathrm{m} / \mathrm{v})$ T4: Ágar $0,7 \%(\mathrm{~m} / \mathrm{v})$. O experimento foi avaliado em um intervalo de tempo de 56 dias, observando-se o desenvolvimento proliferativo.

Para a coleta de dados, observou-se o crescimento das células em diâmetro com o auxílio de um paquímetro digital e para avaliar o crescimento em relação à biomassa foi realizada a amostragem por sacrifício que consiste em retirar três repetições representadas por 1 frasco cada para serem representadas como um ponto que delimitou a curva de crescimento. Em seguida, calculou-se a massa de cada amostra e a partir dos valores adquiridos de biomassa para cada ponto avaliou-se a capacidade das células em se proliferar em cada período de acordo com o tratamento ao qual as mesmas foram submetidas.

\section{Resultados e Discussão}

Os estudos realizados por Corpes et al. (2020) possibilitaram a geração de quatro tipos de calo que foram classificados como embrigênicos, nodais e friáveis sem clorofila e friáveis com aspecto clorofilado. Cada tipo de calo foi obtido com um tratamento diferenciado que se deu a partir do balanço adequado de reguladores de crescimento visando obter biomassa suficiente para avaliar o potencial de produção e acúmulo de metabólitos, especialmente aos pertencentes à classe dos alcaloides. Para o estudo envolvendo a curva de crescimento, houve a escolha dos calos que apresentavam características friáveis sem clorofila, por apresentarem um maior numero de biomassa. Todas estas células foram submetidas à condições controladas em estufas incubadoras a temperatura de $30^{\circ} \mathrm{C} \pm 2^{\circ} \mathrm{C}$ com fotoperíodo de $16 \mathrm{~h}$ (luz/escuro).

Com a obtenção e junção destes dados foi possível gerar uma curva de crescimento para cada tratamento utilizando calos friáveis, o que permitiu realizar uma análise das diversas fases de crescimento destas células. Na Tabela 1, observa-se o crescimento médio destas células em relação ao diâmetro de acordo com cada tratamento, entretanto os gráficos 1, 2, 3 e 4 ilustram o crescimento destes calos de acordo com a massa obtida. Foram realizados quatro tratamentos com três repetições, cada. 
Tabela 1: Crescimento médio de calos friáveis de C.americanum em diâmetro ( $\mathrm{mm})$ de acordo com o tratamento.

\begin{tabular}{ccccc}
\hline & \multicolumn{4}{c}{ Crescimento médio dos calos em diâmetro (mm) } \\
\cline { 2 - 5 } Dias de cultivo & $\mathrm{T}-1$ & $\mathrm{~T}-2$ & $\mathrm{~T}-3$ & $\mathrm{~T}-4$ \\
1 & 0,5 & 0,5 & 0,5 & 0,5 \\
8 & 0,63 & 0,56 & 0,55 & 0,56 \\
16 & 0,71 & 0,66 & 0,79 & 0,69 \\
24 & 0,93 & 0,74 & 0,94 & 0,87 \\
32 & 0,96 & 0,78 & 1,44 & 0,93 \\
40 & 0,98 & 0,81 & 1,55 & 1,09 \\
48 & 1,01 & 0,83 & 1,62 & 1,11 \\
56 & 1,04 & 0,84 & 1,69 & 1,13 \\
$\mathrm{Dp}$ & 0,15 & 0,12 & 0,45 & 0,22 \\
\hline
\end{tabular}

$\mathrm{T}=$ tratamentos, $\mathrm{Dp}=$ desvio padrão. Fonte: Autores.

Os dados de crescimento em diâmetro nos possibilitam observar que houve maior tendência de desenvolvimento celular entre o $16^{\circ}$ e $56^{\circ}$ dia de cultivo para o tratamento 1 , sendo as maiores taxas de crescimento observadas entre o $24^{\circ}$ e $56^{\circ}$ dia. Para o tratamento 2, ocorre uma maior tendência de crescimento a partir do $24^{\circ}$ dia, sendo as maiores taxas de crescimento observadas entre $32^{\circ}$ dia ao $56^{\circ}$. Para o tratamento 3 , ocorre uma maior tendência de crescimento a partir do $16^{\circ}$ dia, sendo as maiores taxas de crescimento observadas entre $24^{\circ}$ e $56^{\circ}$ dia. No tratamento 4 , ocorre uma maior tendência de crescimento a partir do $24^{\circ}$ dia sendo as maiores taxas de crescimento observadas entre o $48^{\circ}$ e $56^{\circ}$ dia. Na tabela acima descrita, pode-se sugerir que o crescimento ainda não apresenta um patamar em que as células atingiram a fase estacionaria, o que descreve que elas se encontram na fase exponencial. Entretanto, pode-se observar melhor esta tendência através dos gráficos que serão nomeados como gráficos $1,2,3$ e 4 .

Os intervalos de tempo acima citados, para o crescimento celular em diâmetro, nos possibilitam observar que a escolha do agente solidificante, bem como a presença e/ou ausência do agente antioxidante, podem interferir no aumento de biomassa celular, pois nesta primeira etapa de avaliação, observou-se que o crescimento celular se deu de forma mais eficiente nos tratamentos 1 e 3, onde o agente solidificante utilizado foi o Phytagel. Ressalta-se que este tipo de solidificante apresenta menor grau de substâncias dissolvidas quando comparadas com outros gelificantes, especialmente com o Ágar.

Também foi possível observar que o balanço dos reguladores de crescimento utilizados no meio de cultura apresentou-se satisfatório, pois as células ainda apresentavam tendência de crescimento, fato que possibilitou gerar as curvas de crescimento relacionadas. Neste sentido, observa-se que o correto balanço entre auxinas e citocininas pode influenciar diretamente no processo de formação e desenvolvimento de calos. Para C.americanum as concentrações que condicionam características satisfatórias para formação de calos exigem que as concentrações de auxinas sejam superiores as de citocininas que podem ser o 2,4-D e o BAP e de acordo com o tipo de calo a ser obtido, estas concentrações podem sofrer variações. (Corpes et al., 2020).

Através do Gráfico 1 é possível observar o crescimento de calos friáveis não clorofilados a partir de raízes. 
Gráfico 1: Curva de crescimento de calos friáveis não clorofilados a partir de raízes

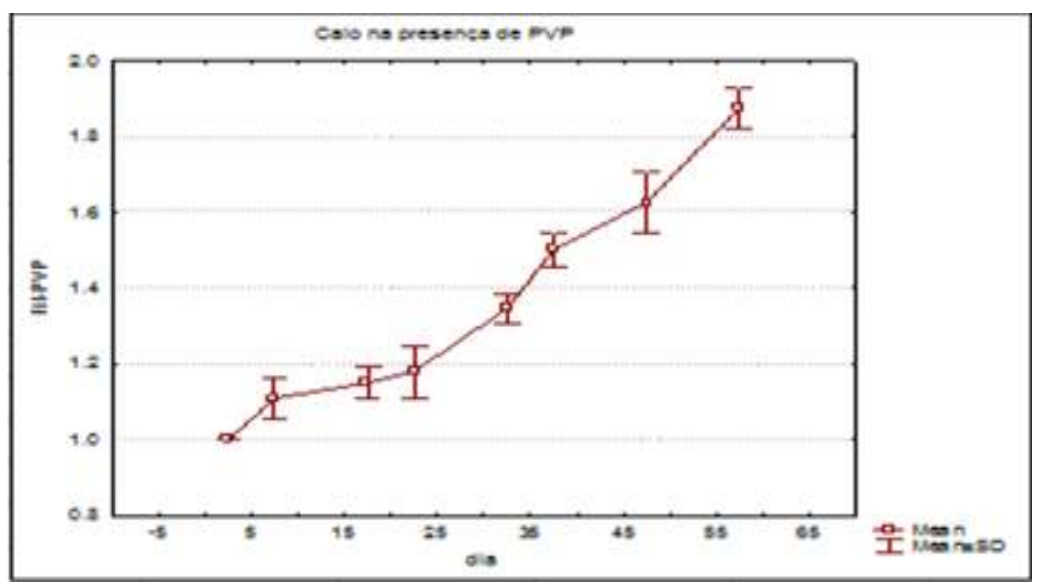

Fonte: Autores.

A partir da análise do Gráfico 1, é possível afirmar que as células que se encontram na presença de PVP combinado com o agente solidificante Phytagel tendem ao crescimento mais acentuado a partir do $24^{\circ}$ dia, permanecendo com esta tendência até o $56^{\circ}$ dia. Durante o período de avaliação do crescimento destas células, foi possível observar que o PVP funciona como um agente antioxidante evitando assim que as células atinjam o estágio de senescência com maior rapidez. Também é possível observar que a velocidade decrescimento se intensifica neste mesmo período, sendo esta caracterizada como a fase exponencial.

Os estudos desenvolvidos por Alcantara, et al. (2017) avaliando o efeito de diferentes antioxidantes e da luminosidade no controle da oxidação de cana-de-açúcar apontam que o PVP na presença de luminosidade apresentou resultados satisfatórios em relação a altura das brotações para esta cultura, pois o mesmo diferiu estatisticamente dos demais tratamentos auxiliando no aumento das brotações, o que não ocorreu nos tratamentos em que havia a ausência de um agente antioxidante. Logo, podemos observar a importância do mesmo para a cultura in vitro.

O Gráfico 2 mostra que as células quando inoculadas em um meio que tenha como agente solidificante o ágar, tendem ao crescimento a partir do $16^{\circ}$ dia, porém é possível observar que este crescimento não é expressivo até o $46^{\circ}$ dia e percebe-se que é a partir deste dia que as células passam a ter um aumento no crescimento que vai até o $56^{\circ}$ dia, sendo o último ponto o mais expressivo em relação ao crescimento. 
Gráfico 2: Curva de crescimento de calos friáveis não clorofilados (massa fresca) oriundos de raízes no tratamento 2.

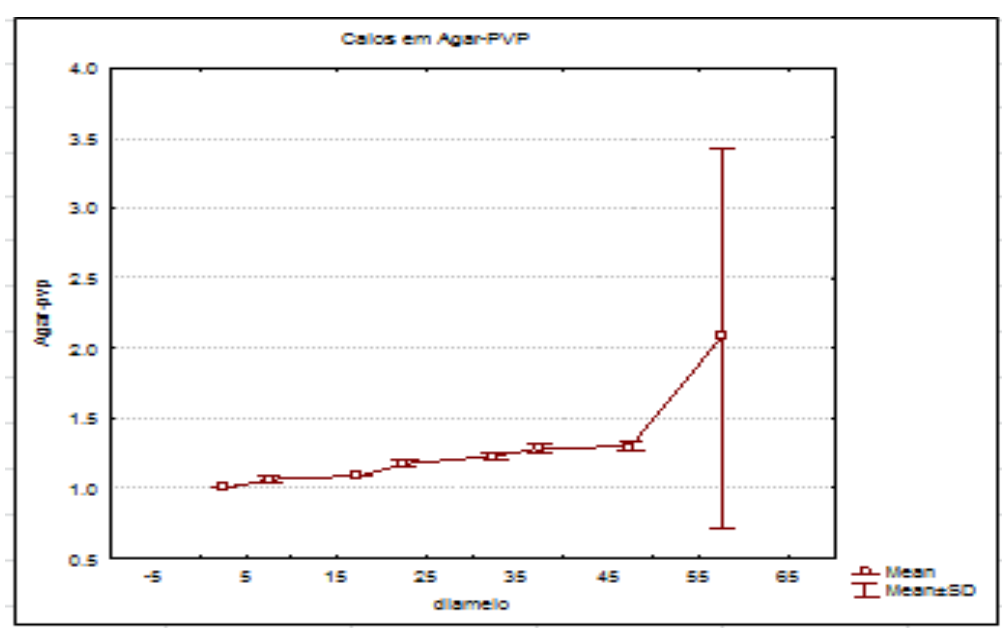

Fonte: Autores.

Segundo Paiva e Paiva, (2001), existem indicações de que o ágar possa causar oxidação nas culturas, ele é constituído de açúcares, galactose e uma fração neutra além da agarose, que possui forte capacidade de gelificar, deste modo o mesmo possuí graus variáveis de pureza, o que influencia na sua capacidade de solidificar e provocar reações com outros agentes no meio de cultura. Segundo estes autores, o mesmo possuí ainda uma grande quantidade de sulfatos, os quais são bastante reativos e também já identificou-se a presença de cobre, elemento capaz de acelerar o processo de oxidação. Alguns tipos de ágar dependendo do fabricante, além do enxofre, podem ainda conter substâncias fenólicas. Todos estes fatores atrelados podem influenciar diretamente no crescimento celular. No Gráfico 3 é possível avaliar o crescimento das células no meio solidificado com Phytagel sem a presença do agente antioxidante. Os dados encontram-se expostos a seguir:

Gráfico 3: Curva de crescimento de calos friáveis não clorofilados (massa fresca) oriundos de raízes no tratamento 3.

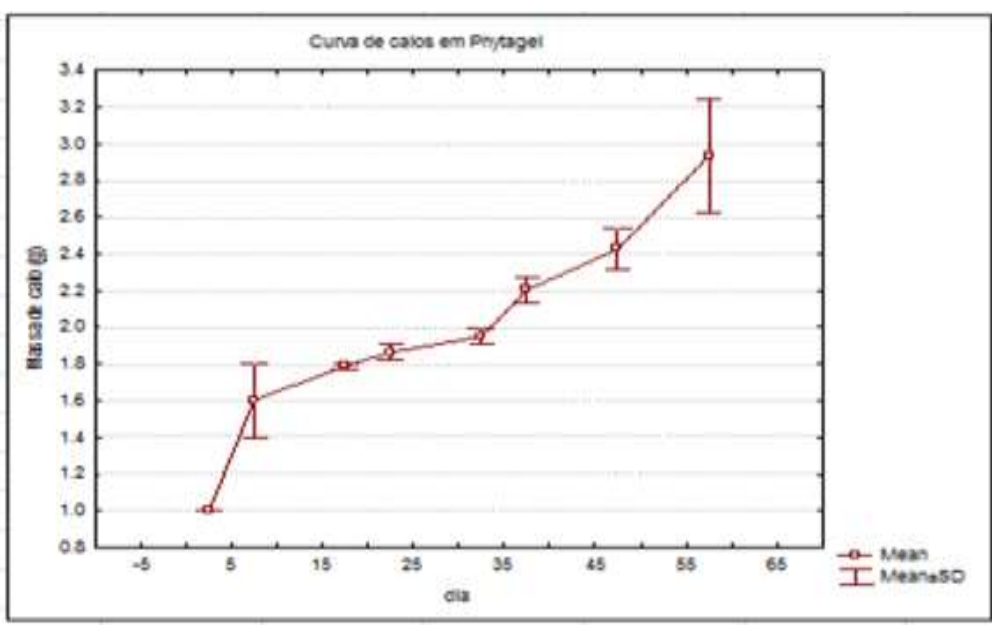

Fonte: Autores.

Através deste gráfico, observa-se uma tendência de crescimento das células a partir do $8^{\circ}$ dia e esta se estende até o $56^{\circ}$ dia. Algo que é importante ressaltar é que a quantidade de massa celular neste tratamento é maior em relação ao tratamento 1 que continha o agente antioxidante PVP + phytagel.

Experimentos realizados por Ribeiro, (2006) com Solanum melongena L. relatam que plântulas crescidas em ágar, agargel ou phytagel possuem diferenças em seu desenvolvimento, pois na presença de phytagel, tanto o número de plântulas e 
o comprimento dos cotilédones desta espécie em questão foram maiores em relação ao meio solidificado com ágar ou agargel. Para C.americanum, observa-se nitidamente um aumento de biomassa nos calos que foram submetidos ao tratamento 3 (MS + Phytagel) em relação ao tratamento 2 em que o meio foi solidificado com MS + ágar + PVP. Neste tratamento observa-se que os calos friáveis não apresentaram oxidações significativas e o aumento de biomassa foi maior em relação aos demais tratamentos, possivelmente devido ao índice mitótico ser maior em relação aos demais tratamentos.

O Gráfico 4 demonstra o comportamento dos calos friáveis no tratamento que contem a presença do agente solidificante ágar sem o agente antioxidante PVP. Os dados encontram-se descritos abaixo.

Gráfico 4: Curva de crescimento de calos friáveis não clorofilados (massa fresca) oriundos de raízes no tratamento 4.

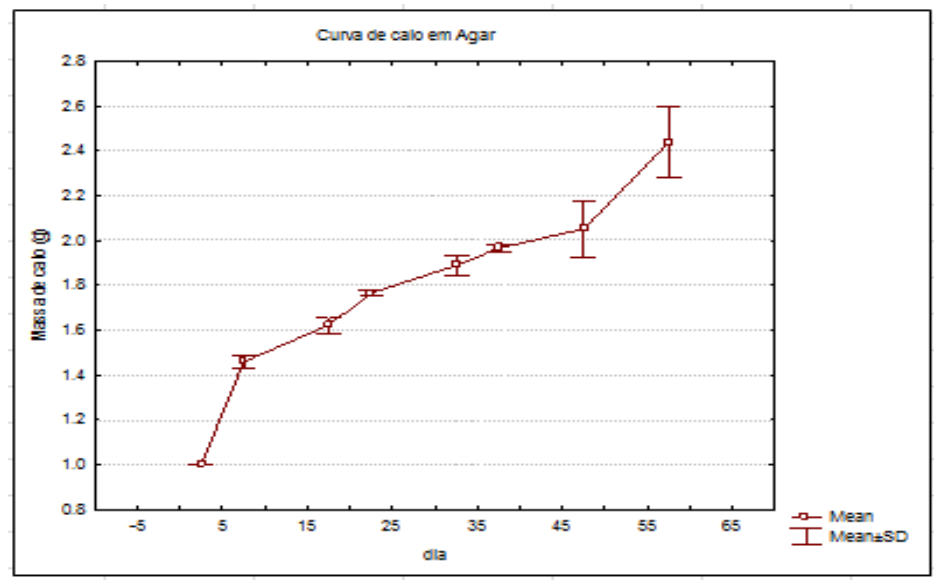

Fonte: Autores.

Neste gráfico é possível o observar que assim como no Phytagel, as células que são cultivadas apenas em ágar sem o PVP, possuem tendência ao crescimento a partir do $8^{\circ}$ dia, porém percebe-se uma ligeira redução na biomassa celular entre o $32^{\circ}$ e o $40^{\circ}$ dia em relação ao tratamento 3. Segundo Scholten e Pierik, (1998a) a maioria das espécies vegetais exibe algum tipo de sensibilidade à qualidade do agente gelificante e esta depende do tipo e da marca comercial, neste caso, o uso do ágar como agente solidificante causou novamente uma redução no crescimento celular quando comparado com o phytagel.

Os autores Bornman e Volgelmann, (1984); Beruto et al., (1999) e Berrios et al.; (1999) relatam que o estado físico do meio pode afetar a difusão dos reguladores de crescimento e nutrientes, modificando a disponibilidade de substâncias solúveis por meio de interações químicas. Os gráficos acima citados nos possibilitam observar que dependendo do tipo de tratamento ao qual o calo é submetido, pode haver diferenças significativas no intervalo de crescimento celular e o tratamento que apresentou respostas mais eficazes em relação ao crescimento celular foi o tratamento 3 .

Na Figura 1 apresenta-se a plântula de C.americanum inoculada in vitro aos 20 dias de cultivo já com raízes que serviram como fonte de explante para o calo friável, objeto de estudo nas curvas de crescimento e na Figura 2 ilustram-se os principais tipos de calo que podem ser gerados a partir de das principais fontes de explantes desta espécie que são raízes e embriões. 
Figura 1: Plântula de C.americanum com 20 dias de cultivo inoculada em meio MS solidificado com Phytagel.

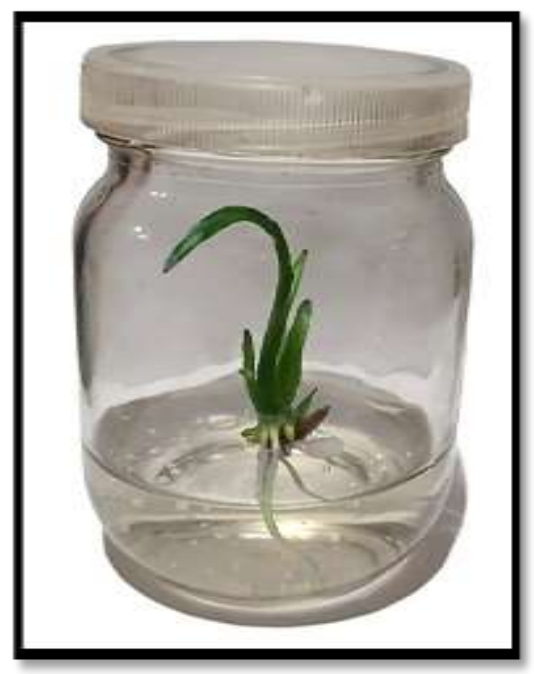

Fonte: Corpes (2020).

Figura 2: Possíveis calos a serem obtidos a partir do cultivo in vitro de C.americanum com destaque para o calo friável (a), calo friável clorofilado (b), calo nodal (c) e calo embriogênico (d) inoculados em meio MS solidificado com Phytagel contendo a presença dos reguladores de crescimento 2,4-D; BAP e do agente antioxidante PVP.

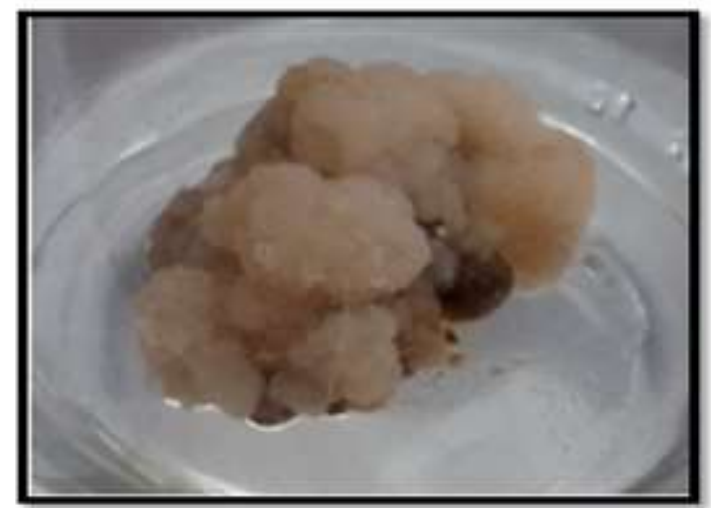

(A)

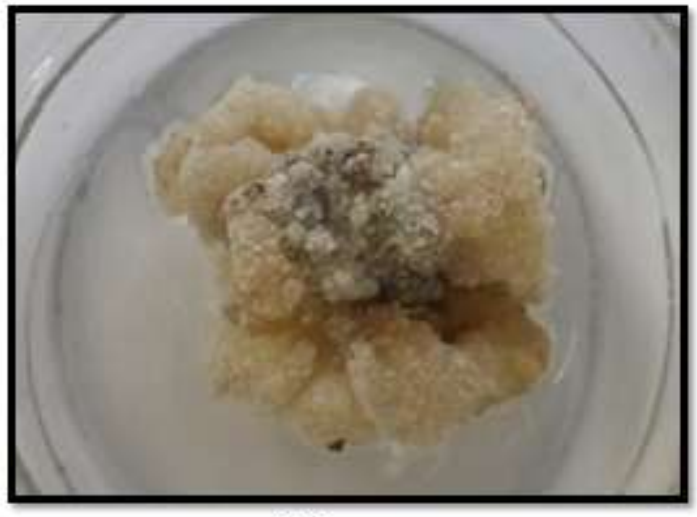

(C)

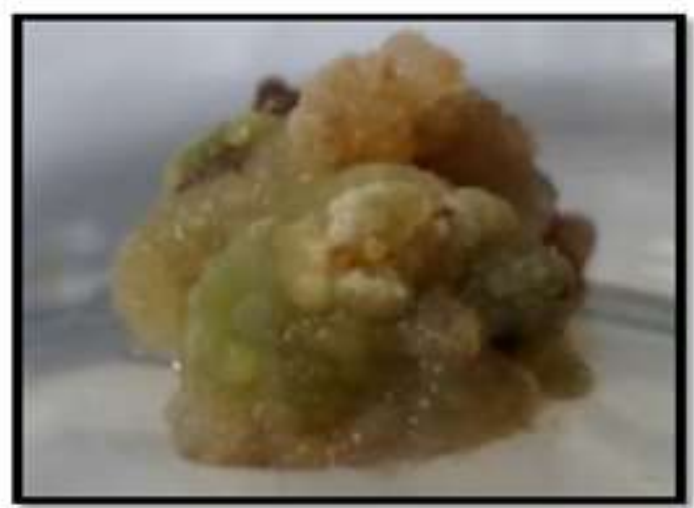

(B)

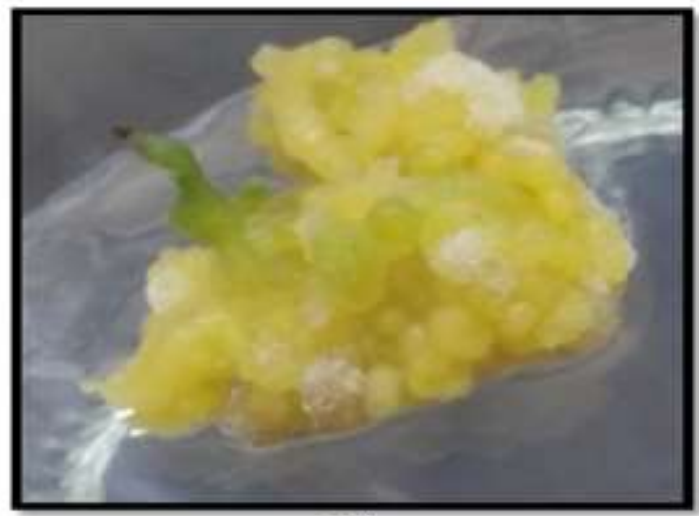

(D)

Fonte: Corpes (2020) 


\section{Considerações Finais}

Os resultados apresentados nos permitem concluir que o estudo das curvas de crescimento em Crinum americanum são importantes para avaliar as principais etapas do desenvolvimento celular desta espécie. Observou-se que quando os calos friáveis são inoculados com o correto balanço entre os reguladores de crescimento no meio que contenha o agente solidificante Phytagel, as células tendem a crescer com maior velocidade e consequentemente o ganho de biomassa é maior. No que diz respeito ao agente solidificante ágar, as células crescem com menor velocidade e quando não ocorre à adição de um agente antioxidante como o PVP ao meio de cultura, as mesmas tendem a senescer de forma mais rápida. Este estudo poderá ser de grande utilidade para pesquisas futuras que tenham como enfoque o estudo dos principais metabólitos secundários contidos na espécie bem como temáticas que abordem a embriogênese somática e/ou organogenese na espécie em questão.

\section{Agradecimentos}

Os autores agradecem à Universidade Federal do Pará, ao Programa de Pós-Graduação Biotecnologia e a Coordenação de Aperfeiçoamento de Pessoal de Nível Superior - Brasil (CAPES) - Código de Financiamento 001.

\section{Referências}

Alcantara G. B. et al. (2017). Efeito de diferentes antioxidantes e luminosidade no controle da oxidação e multiplicação in vitro de genótipos da cana-deaçúcar. Revista Spacios, 47 (38), 22.

Almeida. G. M \& Rodrigues, J. G. L. (2016). Desenvolvimento de plantas através da interferência de auxinas, citocininas, etileno e giberelinas. Brazilian Journal of Applied Technology for agricultural Science. 3 (9), 111-117.

Araújo, S. F. et al. (2018). Biotecnologia Vegetal: Indução de calos da espécie Crinum americanum L. (Amaryllidaceae). In: Santos, S.; Lucas, F. C. A.; Junior, M. R. M.; Santos, A. S. (Org.) Bioculturalidade, Conservação e Biotecnologia na Amazônia Oriental. pp (375-389). Curitiba, PR: Editora CRV.

Berkov, S. et al. (2012). GC-MS of Amaryllidace ousgalanthamine-type-alkaloids. Journal of Mass Spectrometry, 47 (8), $1065-1073$.

Berrios, E. F., L. et al.(1999). Influence of genotype and gelling agents on in vitro regeneration by organogenesis in sunflower. Plant Cell, Tissue and Organ Culture. (59), 65-69.

Beruto, M. P et al. (1999). Influence of agar on in vitro cultures: I Physicochemical properties of agar and agar gelled media. In vitro Cellular \& Developmental Biology - Plant, (35), p.86-93.

Bornman, C. H. \& Vogelmann, T. C. (1984). Effect of rigidity of gel medium on benzyladenine induced adventitious bud formation and vitrification in vitro in Picea abies. Physiologia Plantarum, (61), 505-512.

Cordeiro, I. M. C. C., Lameira, O. A., Ohashi, S. T. \& Rosal, L. F. (2004). Efeito de BAP sobre a proliferação de brotos in vitro de Schizolobium amazonicum (paricá). Cerne, 1 (10), 118-124.

Corpes, R. S, et al. (2019). Comparison of Volatile Profile and Antioxidant Activity of Piper divaricatum G. Meyer (Piperaceae) Using Cuttings and Cell Tissue. Journal of the Brazilian Chemical Society, n.11 (30), 2291-2298.

Corpes. R. S, et al. (2020). Germinação in vitro, formação de plântulas e Produção de calos de Crinum americanum L. (Amaryllidaceae). Uma alternativa para produção de metabólitos secundários. In: Silva-Matos; R. R. S.; Oliveira, A. R. F.; Albano-Machado, F. G. (Org.) Floricultura, plantas ornamentais e cultura de tecidos de plantas. pp (12-23) Ponta Grossa, PR: Atena Editora.

Costa, A. S. (2006). Sustentabilidade da Produção de Alecrim pimenta (Lippia sidoides Cham.): Micropropagação visando à conservação in vitro. $70 \mathrm{f}$. Dissertação (Mestrado), Universidade Federal de Sergipe, SE.

Fagundes. E. (2020). Fitorreguladores no crescimento, produtividade, aspectos fisiológicos e nutricionais em videiras Vitis vinífera. 124 f. Tese (Doutorado) Universidade do Estado de Santa Catarina, SC.

Jardim. L. S. et al. (2010). Efeito de diferentes reguladores de crescimento na regeneração in vitro de pau-rosa (Aniba rosaeodora Ducke). Acta Amazonica, 2 (40) $275-280$.

Murashige, T. \& Skoog, F. (1962). A revised medium for rapid growth and bioassys with tobacco tissue cultures. Physiologia Plantarum, (15), $473-479$.

Oliveira. K. S et al.(2019). Influência de reguladores de crescimento e do tipo de explante na morfogênese in vitro de Hancornia speciosa Gomes. Revista Desafios, 4 (6).

Paiva, R. \& Paiva, P. D. O. (2001). Cultura de tecidos, Lavras: UFLA/FAEPA.

Ribeiro J. P. N et al. (2009). Efeitos alelopáticos de extratos aquosos de Crinum americanum L. Revista Brasileira de Botânica, 1 (32), $183-188$. 
Research, Society and Development, v. 10, n. 12, e299101220378, 2021

(CC BY 4.0) | ISSN 2525-3409 | DOI: http://dx.doi.org/10.33448/rsd-v10i12.20378

Ribeiro, A. P. O. (2006). Influência do genótipo, agentes gelificantes, precursor (ACC) e inibidores (AVG e STS) do etileno e tipo de vedação na morfogênese in vitro de berinjela (Solanum melongena L.). 127 f. Tese (Doutorado) - Universidade Federal de Viçosa, MG.

Scholten, H. J. \& Pierik R. L. M. (1998a). Ágar as gelling agent: diferential biological effects in vitro. Scientia Horticulturae. (77), 109-116.

Singh, M. B. \& Bhalla, P.L. (2006). Plant stem cells carve their own niche. Trends in Plant Scienc, (11), 241-246.

Soares, G. de A. (2003). Aspectos do cultivo in vitro do ingazeiro [Inga Vera Willd. subsp. affinis (DC) T. D. Penn]. 90 f. Dissertação (Mestrado) Universidade Federal de Lavras, MG.

Yew, C. K., et al. (2010). The effect of cytokinins on in vitro shoot length and multiplication of Hymenocallis littoralis. Journal of Medicinal Plants Research, 24 (4), 2641-2646. 